\title{
An evaluation of the effectiveness of Community Support grants for Early Childhood Education to enhance educational access in Nyandarua District, Kenya.
}

\author{
Miriam Kirathi
}

\begin{abstract}
Any investment programme in ECDE aims at an overall programme of expanding access in order to enhance ECDE services that are of high quality for the children aged 4 years to 5 years. Such children are children living in difficult circumstances such as Arid and Semi Arid lands (ASAL), urban slums and other poverty stricken areas in Kenya. The Kenya government has proposed to achieve this goal for the ECDE investment programme under Kenya Education Sector Support Programme (KESSP) by establishing a policy guideline which is national and service standards for ECDE, enhancing capacity building and community mobilization and giving support grants to the communities. Other strategies are reviewing of the ECDE curriculum, promoting ECDE health and nutrition and preparing the children ready for primary schooling. The evaluation was concerned with the effectiveness of the implementation of Community Support Grant programme in order to enhance enrolment in ECDE for children aged 4-5years. The objectives of the study was to evaluate whether enrolment in ECDE for learners aged 4-5years have been enhanced after the implementation of community Support Grant, challenges facing the implementation of Community Support Grant and the way forward in implementing Community Support Grant in Murungaru Zone Nyandarua South District. The paper has lots of significance to ECDE policy makers who need to enforce the ECDE policies as opposed to the way the policy is being practiced. The ECDE children stand to benefit since the policies and practice will be in tandem. The transformation of society can't be complete if the ECDE sector appears to be forgotten; hence national development remains a dream. A summative evaluation was done guided by Scriven's Model of Expert -Oriented Evaluation Approach. The worrying reality however is that despite the Government's effort in financing all the ECDE centres in Murungaru Zone, some of the schools have been registering a drop in enrolment. .Some of the challenges facing the implementation of Community Support Grant is; Free Primary Education Policy, Poverty, attitude, misappropriation of funds, parents level of education and inadequate funds. The paper concludes that ECDE being bedrock to the foundation of learning, serious considerations on enrolment and challenges facing the implementation need to be enforced in order to benefit the child.
\end{abstract}

Key words: Community Support Grant, Early Childhood Education.

\section{Introduction}

Early childhood refers to the period starting from the prenatal stage of human development through the transition into early learning period in primary school. During this time, the child develops through physical, cognitive, linguistic, and socio emotional domains of human development. According to KESSP 2005, Kenya Education Background 2005, MOEST 2009 policy Framework Draft 2012, over 200 million children in the developing world fail to reach their developmental potential due to lack of the required support in their development resulting from nutritional deficiencies, poverty, and inadequate learning opportunities. These services and care links the young child in cognitive, emotional, social and physical developmental processes.

The provision of care and services of ECDE is an integration effort of households, communities and the Government and may be structured into 0-3 years and 4-5 years. The main focus of any government Education policy on the 4-5 years group of children is to provide holistic and integrated development programme that is designed to meet the child's social, moral, emotional, cognitive, spiritual and physical needs.

Basically, the Kenya government has placed the analysis of national research and the already identified best practice lessons from existing ECDE programmes of Kenyan projects and investment programme under KESSP. In this respect, the goals of the international conventions such as the 1989 Convention on the Rights of the Child (CRC) has been the main Kenya government's reason to come up with the KESSP programme. Others include the Dakar Framework of Action on EFA, the 1990 Jomtien Declaration on Education for All (EFA) and the Millennium Development Goals (MDGs).

The government outlines a number of policy measures about ECDE in the sessional paper. This includes:

- Incorporation of legal framework to develop and implement an overall ECDE policy.

- Intensify resource mobilization and capacity building in order to empower stakeholders in managing ECDE facilities effectively. 
- Integrating children aged 4-5 years into primary school life by way of preparing modalities for mainstreaming ECDE as part of basic education in the country by the year 2010.

- Developing a comprehensive National framework to guide the formulation and implementation of a national curriculum, the integration of alternative curriculum delivery programmes, a teacher training programme which culminates in standard certification and basic ECDE requirements.

The Government of Republic of Kenya (GOK) has demonstrated its commitment to the well being of young children, this is by signing various global policy frameworks. These forums underscore the importance of Early Childhood Education and Development, and identify challenges facing ECD sub sector (Republic of Kenya 2006)

The government through Sector Wide Approach to Programme Planning (SWAP) and development partners worked together to come up with the Kenya Education Sector Support Programme (KESSP). The programme Comprised of twenty three investment programmes which focused on the education sector as a whole. KESSP was basically founded to oversee the achievement of the Education for All (EFA) policy and through it the government commits itself to the attainment of the millennium development goals (MDG). The broad objective is to provide an education which is all inclusive so that every Kenyan gets quality education and training no matter his/her socio-economic status or background and also which is accessible and relevant (MoE, 2009\& 2010).

KESSP is a programme through which the government of Kenya, (MOE), development partners ,civil society, community and the private sectors come together to support education sector development for the period 2005-2010. KESSP fits within the framework of National Policy set out in the Economic Recovery Strategy (ERS).

Early Childhood Development and Education programme, (ECDE) is among the twenty three investment programmes mentioned in KESSP (Republic of Kenya, 2005 as in MOE 2009).

The overall goal of the ECDE investment programme is to enhance access, equity and quality of education for all children aged 4-5 years, especially the most vulnerable children, living in Arid and Semi Arid Lands (ASALS), urban slums and pockets of poverty. By 2007, access to ECDE services was low at 35\%. The national target was to improve the access to ECDE services to $60 \%$ by 2010 (UNESCO 2005, MOE 2009, as in Policy Draft 2012). The MoE has to ensure that all children in the age bracket of 4 to 5 years, especially girls and children living in difficult circumstances have access to quality services in ECDE centres (Republic of Kenya, 2007).

One of the strategies the Ministry continues to apply to achieve these targets is the provision of Community Support Grants (CSG) to selected ECDE centres across the country. The Community Support Grants programme is an initiative of the MOE to assist ECDE centres and the communities in the disadvantaged areas of Kenya, to improve access to quality ECDE for children aged 4-5 years. The CSG is in the line with the Seasonal Paper 5 in which the government has come up with the ECDE sub sector policy: To address this policy, it has been strategic to design a programme of building community capacities for them to develop and equip ECDE centres in partnership with stakeholders. Community Support Grants (CSG) has been proposed as one of the ECDE investments under KESSP so as to achieve the overall goal of the programme (Republic of Kenya 2005, MOE 2009 as in Policy Draft 2012)

CSG is paid by the MOE directly to a special bank account established by each ECDE centre. Before funds are sent to the ECDE centre, the ECDE management committee must prepare an ECDE centre improvement plan which explains how the centre will use the CSG to increase the enrolment and improve the quality of education of children aged 4 to 5 years. The ECDE centre improvement Plan is formally presented and approved at a special meeting of parents and community members before a centre can receive CSG from the MOE. The ECDE management committee members are trained on how to develop a quality centre improvement plan and how to successfully manage their CSG (Republic of Kenya, 2007, MOE 2009)

The CSG programme is managed in three levels. The head office, whose key responsibility is National coordination of the Community Support Grants programme, provide support and advice to districts and national programme, planning, monitoring, evaluation and reporting. The District Education Office's responsibility is to support and advice all ECDE centres in the district Selected to receive Community Support Grants, train the ECDE management committee and Programme monitoring and reporting to District Education Boards and the MOE head office Finally the community (management committee) will produce an ECDE centre improvement Plan, consult members of community, implement the ECDE centre plan, and manage the CSG monitor the use of the funds and report to the District Education Officer (Republic of Kenya 2007, MOE 2009)

The CSG is calculated using per pupil grant. This is to encourage ECDE centres to increase their enrolment. At the end of each year the ECDE management committee is required to report the total number of the children enrolled in the centre to the District Education Officer. The ECDE management committee is required to maintain or increase this enrolment level over the following year. The District Education Board has 
the authority to discontinue a grant given to an ECDE centre that fails in its responsibility to deliver services that are of quality in education (Republic of Kenya, 2005).

The Community Support Grants aims to improve the infrastructure that exists in the ECDE centres such as the semi-permanent and permanently constructed classrooms, learning materials, toilets and school furniture. Putting up such infrastructure in schools is basically the most challenging undertaking parents may encounter. Further, the programme offers a top up for teacher's salaries even though it is the parents' responsibility to pay the ECDE teachers. The grants are channelled through established bank accounts in recognised banks to the selected centres. The accounting of the money provided through the grant is done by following a detailed guideline by the management committees of the centres which are trained on basic financial management (Republic of Kenya, MOE).

The Kenyan government instituted ECDE Community Support Grants as one of the major component of the 23 national investment programmes. The Ministry of Education expected that all the ECDE centres that benefited from CSG have improved on access, equity and quality of services given. Despite the government's efforts the NER had not hit the government's target of $60 \%$ by 2010 . According to the Ministry of Education Policy Frame Work Draft April 2012)

Educational access and participation at the ECDE level were still found to be low with a Net Enrolment Rate (NER) of $42 \%$ and $50 \%$ in 2009 and 2010 respectively. This means that the remaining $58 \%$ and $50 \%$ of the school-age going pupils were not in school then. Furthermore, only $60 \%$ of the then administrative Provinces had a NER above the national figure of $42 \%$ with North Eastern Province taking the lowest.

Access of ECDE education is one of the goals of KESSEP report 2005.The study sought to evaluate the effectiveness of the implementation of Community Support Grant in Murungaru Zone Nyandarua South District in order to enhance enrolment of children aged 3-5years.

\section{Methodology}

The study was an evaluative initiative. It was based on Scriven's model of evaluation which emphasis on weighing and selection of goals and objectives of the program and indentifying the areas of success or failures. An educational programme is supposed to be driven by the spirit of the set goals and objectives the study started by getting a clear description of the programme objectives in ECDE. An evaluation requires that the objectives be clearly articulated and expressed in ways that are measurable. The objectives of the evaluation was to evaluate the effectiveness of the implementation of community support grant in Murungaru Zone Nyandarua South District in order to enhance enrolment of children aged 4-5 years in ECDE. The evaluator used secondary data from the DEO's office in Nyandarua South District.

\section{Findings}

Murungaru Zone has eleven public ECDE centres and all were involved in the study

Table 1; Enrolment of children aged 4-5 years in ECDE schools in Murungaru Zone

\begin{tabular}{|l|l|l|l|l|}
\hline Name of school & Year-2011 & Year-2012 & Year-2013 & Total \\
\hline Mwiruti & 48 & 32 & 32 & 112 \\
\hline Kimuri & 42 & 47 & 61 & 150 \\
\hline Kabata & 48 & 65 & 46 & 159 \\
\hline Kihumbu & 55 & 68 & 15 & 138 \\
\hline Mwihoko & 6 & 35 & 41 & 82 \\
\hline Hiayu & 50 & 51 & 58 & 159 \\
\hline Ndarachaini & 30 & 34 & 30 & 94 \\
\hline Murungaru & 29 & 34 & 46 & 109 \\
\hline Mugumoini & 25 & 45 & 25 & 95 \\
\hline Mwihoti & 18 & 19 & 31 & 68 \\
\hline Michinda & 3 & 11 & 46 & 60 \\
\hline Total & $\mathbf{3 4 5}$ & $\mathbf{3 6 7}$ & $\mathbf{3 8 9}$ & $\mathbf{1 1 0 1}$ \\
\hline
\end{tabular}

The study found out that all the public ECDE centres are beneficiaries of Community Support Grant during the years under study. The total enrolment of the children as shown in the figure indicates that some schools had a steady improvement on enrolment; others have unstable enrolment while others have decreased in enrolment trend. However the overall enrolment has been improving year after year.

The second objective of the study was to determine the challenges facing the implementation of community support grant in Murungaru

Challenges Experienced in the Implementation of Community Support Grants; 


\section{Irregular disbursement of CSG funds}

- CSG funds take a long time before being remitted to the ECDE Centres and the remittance is not regular and therefore making difficult to plan for the utilization of the funds.

- -In adequate funds. According to the head teachers the funds disbursed are not adequate and sometimes $t$ are not enough to accomplish a given project. This makes it difficult to meet the needs of the ECDE centre therefore affecting the enrolment.

- -Parents perception; the introduction of CSG made the parents to think that ECDE education is free. Some parents refused to support the ECDE centres in any way. This makes it difficult to run the ECDE centres since the CSG fund provides only a top up for teacher's salaries and the rest of the salary is to be paid by the parents. Lack of teachers salaries make teachers to look for greener pastures and the children are left alone/ which causes the drastic reduction in enrolment in some schools.

\section{FPE policy;}

The FPE policy have greatly affected the ECDE enrolment, this is because the parents prefer to wait until their children reach 6years which is primary school going age and enrol them to standard one which is free instead of taking them to ECDE which is not free.

Poverty level; some parents are very poor such that they are not able to pay the little fee charged at the ECDE centre some are not even able to feed their children and the children go to the ECDE centre with food. Others shy off to send their children to the ECDE centres without food.

\section{Recommendations}

i).The government should therefore provide free or affordable ECDE services and hence make it compulsory for all children aged above 4-5years.

ii).The government should disburse funds regularly so that the ECDE management can be able to plan for the utilization of funds.

iii).The government should make ECDE free so that the children of poor parents can be enrolled

iv). The government should introduce feeding program in order to motivate the poor parents who shy off to enrol their children in ECDE centres due to lack of lunch

v).The Education office should enhance monitoring and evaluation exercise of the funds. This would create seriousness among the head teachers on the management of the funds and eliminate cases of corruption.

vi). The head teachers should make sure that all the funds intended to benefit any particular centre in the district are properly utilized. They should ensure that the funds only benefit the ECDE centres meant to benefit and that the right projects are carried out.

\section{Conclusions}

From the finding of the study it has been concluded that, Community Support Grants have some impact on enrolment in public ECDE centres in Murungaru Zone Nyandarua South District for children aged between 4-5years

It has been concluded that there was an overall increase in total enrolment of children aged 4-5years.

It was also concluded that not all ECDE centres that benefited from the implementation of CSG had improved on enrolment since some were dropping in enrolment.

\section{References}

[1]. Ministry of Education. (2009). Education Facts and Figures 2008-09. Nairobi: MOE

[2]. Ministry of Education Science and Technology. (2005). The Background Report of Kenya, report for the UNESCO/OECD Early Childhood Policy Review Project. Nairobi: MOEST.

[3]. Republic of Kenya. (1988). Education and Manpower Training for the Next Decade and Beyond (Kamunge Report). Nairobi: Government Printer.

[4]. Republic of Kenya. (2005). Kenya Education Sector Support Programme (KESSP) 2005-2010. Nairobi: Office of the President and Ministry of Home Affairs.

[5]. Republic of Kenya. (2006). National Early Childhood Development Policy Framework. Nairobi: Government Printer.

[6]. Republic of Kenya. (2011). Kenya Budget Statement for the Fiscal Year 2011/2012. Nairobi: Ministry of Finance. 